\title{
COMPREENDENDO A EXPERIÊNCIA DO SOFRIMENTO DE MULHERES NA RELAÇÃO AMOROSA
}

\author{
Understanding of the suffering experience of women on loving sexual relation \\ Conprensión de la experiência del sufrimiento de mujeres en la relación amorosa
}

Ana Regina de Lima Moreira

Elza Maria do Socorro Dutra

\begin{abstract}
Resumo: A escuta clínica de mulheres que permanecem no sofrimento amoroso gerou indagações que apontavam para a singularidade da experiência em questão, considerando-se os aspectos culturais e históricos (gênero e amor-romântico) que pareciam permear tal experiência. Este trabalho objetiva compreender a experiência de sofrimento constante de mulheres na relação amorosa. A população estudada foi composta de seis mulheres que estavam vivendo a experiência em questão. Os dados foram colhidos através da entrevista semi-aberta. A narrativa foi o instrumento de acesso à experiência. A análise fundamentou-se no referencial fenomenológico-existencial. De acordo com os resultados obtidos, entendemos que o sofrimento das participantes na relação amorosa revela, sobretudo, um self ou modo de estar no mundo, de perceber-se, marcado pelo medo da solidão, do desamor, medo de empunhar a própria vida e dar origem a um modo de viver e de amar realmente novos.
\end{abstract}

Palavras-chave: Sofrimento de mulheres; Pesquisa fenomenológica; Relação amorosa; Self.

Abstract: The clinical hearing women that stand in the suffering Love had led to some enquiries pointing at the singularirty of the meaning experience, considering historic and cultural aspects (genre and romantic Love) that seemed to permeat such experience. This work intends to understand the constant suffering experience of women on loving and sexual relation. The studied population was composed with six women who were living the meaning experience. Data were collected through partlyopen interview. The narrative was the instrument to acess experience. The analysis was based on fenomenological-existencial approach. According to the obtained results, we understand that the suffering of the sharing, on loving relation, reveals above all, a self or a way of being in the world, to be perceived, marked by fear of loneliness, lack of love, fear of grasping of their own lives and to give birth to a really new of live and lovge.

Keywords: Suffering in women; Phenomenological research; Loving and sexual relation; Self.

Resumen: La escucha clínica de mujeres que permanecem em el sufrimiento amoroso generó indagaciones que apuntaban a la singularidad de esta experiência teniendo em cuenta aspectos culturales e históricos (gênero y amor-romántico) los cuales pareciam permear esta experiência. Este estúdio tiene como objetivo comprender la experiência del sufrimirnto constante de mujeres em la relación amorosa. La población estudiada está compuesta de seis mujeres, quienes viviam la experiência. Los datos fueran recopilados a través de entrevista semi-abierta. La narrativa fue el instrumento de acesso a la experiência. El análisis se fundó em el referencial fenomenológico-existencial. De acuerdo com los resultados obtenidos, comprendemos que el sufrimiento de las participantes, em la relación amorosa revela sobretodo um self o manera de estar em el mundo, de percibirse, marcado por el miedo a la soledad, al desamor, miedo de manejar la própria vida y dar origen a maneras de vivir y de amar realmente nuevas.

Palabras-clave: Sufrimiento; Investigación fenomenológica; Relación amorosa; Self.

\section{Introdução}

Em nossa vivência profissional como psicóloga atuando em consultório privado e em centro de saúde da rede pública frequentemente nos deparamos com a narrativa de mulheres de uma experiência de sofrimento constante na vida amorosa. Vale ressaltar que o sofrimento ao qual estamos nos referindo é aquele vivido pela mulher de forma constante, predominando sobre as suas vivências de prazer e bem-estar na esfera da relação amorosa heterossexual. Tal relação está sendo considerada como de natureza afetivo-sexual, na perspectiva da mulher e que se refere à sua vida amorosa, não implicando o critério de coabitação da díade.

A pesquisa relatada neste artigo objetivou compreender a experiência da mulher que permanece no sofrimento na relação amorosa. A característica de permanência ora atribuída ao sofrimento, não significa a ideia de que as mulheres participantes da pesquisa permanecerão ad infinitum no sofrimento amoroso. Nosso entendimento é de que elas passam por um período de convivência relativamente duradoura com o parceiro, segundo evidenciam suas falas, em que predominam momentos de insatisfação, angústia, dor, ou outras expressões de sofrimento. 
Desse modo, tais mulheres demonstram, através de suas narrativas, que a relação amorosa tem ocupado um lugar desfavorável em detrimento de vivências prazerosas.

Ao longo do processo de investigação, interrogamo-nos sobre os aspectos subjetivos que não só permeiam a experiência em questão, mas, além disso, contribuem para tal. Ao lado disso, perguntamo-nos sobre a influência dos valores e papéis sociais e culturais relacionados ao "modo de ser mulher", na vivência desse sofrimento. Observamos, a despeito das significativas conquistas femininas das últimas décadas, que os padrões, valores e normas culturais cultivados no passado continuam presentes, permeando a existência da mulher, sua auto-imagem e o modo como ela se relaciona amorosamente, embora reconheçamos que nos dias de hoje seja diferente dos tempos de outrora. Dentro dessa perspectiva, indagamos ainda sobre a importância que a idealização do amor romântico pode ter na existência do fenômeno em investigação.

Conforme o nosso entendimento, a experiência subjetiva diz respeito ao mundo interior do ser humano, àquilo que ele sente como particular, único, genuíno e que se expressa através do self ou autoconceito. Com esse entendimento, adotamos a perspectiva teórica da Teoria de Personalidade desenvolvida por Carl Rogers na Terapia Centrada no Cliente. Nessa concepção teórica, destacamos o constructo self, ou autoconceito, definido por Rogers (1959), e após as contribuições de Eugene Gendlin (1962), como a configuração perceptual do indivíduo sobre o seu estar no mundo, a cada momento da existência, de acordo com a abertura ao fluxo de experiências que se processam. É esse entendimento do self que adotamos neste trabalho. Consideramos que o self, à medida que se desenvolve, é permeado por valores, expectativas sociais, modos de pensar, sentir e agir característicos do contexto no qual o ser humano está inserido. Tratandose especificamente da mulher, observamos que, historicamente, lhe têm sido reservados modos de existência muito específicos.

\section{Contextualizando o Self ou Sobre Gênero, Amor e Sofrimento}

Neste trabalho, assumimos a categoria de gênero como perspectiva relacional, isto é, não como diferença sexual, mas uma construção social e histórica do que é ser homem ou mulher em uma dada época e cultura (Silva, 2000; Negreiros \& Feres-Carneiro, 2004; Braga, 2005). Desse modo, acreditamos que, assumindo a categoria de gênero como perspectiva relacional, ampliamos a nossa compreensão das diversas expressões do sofrimento das mulheres na sua vida amorosa, pois entendemos que o sentido atribuído por elas a tal experiência está permeado pelos significados do contexto sócio-histórico. Nessa perspectiva, pensamos como Biasoli-Alves (2000), que, mesmo diante das mudanças e rupturas na imagem e no papel da mulher ao longo da história, os valores e expectativas cultivados continuam presentes, embora com outros contornos, influenciando o modo feminino de estar no mundo.

No que diz respeito ao mundo ocidental observa-se, nitidamente, que, na história da humanidade, a condição das mulheres tem “(...) refletido categoricamente a perspectiva da ocupação do espaço público e privado, a partir dos papéis socialmente construídos como de homens e de mulheres" (Silva, 2000, p. 40). No entanto, as derradeiras décadas do século XX evidenciaram um modo diferente de a mulher estar no mundo, ou seja, ela passou a participar ativamente dos acontecimentos de ordem política, econômica e social. Com isso, houve uma relativa flexibilidade no que diz respeito às atribuições assumidas por homens e mulheres, tanto na relação amorosa e familiar, quanto em outros contextos sociais, possibilitando o estabelecimento de uma relação menos desigual entre ambos.

Contemporaneamente, percebemos que os papéis tradicionalmente atribuídos aos homens e às mulheres estão sofrendo alterações gradativas no sentido de tornarem-se mais igualitários. Nesta linha de pensamento, Almeida e Jablonski (2011), juntamente com Maux e Dutra (2010), observam que as transformações na relação intergênero têm levado tanto o homem como a mulher a realizarem mudanças no modo de agir em busca de um relacionamento afetivo mais satisfatório. Contudo, as desigualdades de gênero ainda prevalecem, muitas vezes dificultando a convivência do par amoroso.

Goldberg (conforme citado por Giddens, 1993), afirma que "as mulheres ainda são as principais agentes da criação dos filhos e das tarefas domésticas" (p. 172). Vaitsman (2001), no contexto brasileiro, ratifica essa afirmação, defendendo o ponto de vista de que essa situação pode significar sobrecarga de trabalho, em vez de emancipação. Uma das conclusões apresentadas por Medeiros (2003), em sua pesquisa realizada na cidade do Natal (RN), sobre a "doença dos nervos", revela que a submissão aos maridos e o excesso de responsabilidades domésticas “(...) contribuem para o desencadeamento dos sintomas de nervos" (p. 112). Isso nos faz refletir sobre a proximidade existente entre as questões de gênero, relacionamento amoroso e sofrimento, além de nos remeter ao nosso cotidiano profissional, no qual comumente encontramos mulheres que expressam o sofrimento vivido na relação amorosa através do "problema de nervos". Este envolve, segundo a autora anteriormente citada, uma polimorfia de sintomas (fisiológicos, físicos e psíquicos), além de questões tais como gênero, contexto sociocultural e econômico, abuso da medicação, dentre outros.

Da mesma forma que as desigualdades de gênero presentes na nossa cultura influenciam a mulher na formação de um self que contribui para que ela vivencie o sofrimento permanente em sua vida amorosa, pensamos que a idealização do amor romântico também influencia 
o modo como ela se percebe no mundo e, portanto, a sua experiência de sofrimento. Mesmo tendo surgido há três séculos, o amor-romântico, tal como designado por Costa (1999) e ressaltado por Rebouças e Dutra (2011), continua presente em traços ainda mantidos, embora de maneira diferente de tempos atrás, tendo em vista o surgimento de novas configurações amorosas no mundo atual, afetando o modo como a mulher se relaciona amorosamente.

Embora concordando com Féres-Carneiro (1998) e Anthony Giddens (1993) sobre a importância das conquistas femininas para a fragilização do amor romântico, o que favoreceu a emergência de novas configurações das relações amorosas, compreendemos que essas mudanças e os ideais do amor romântico coexistem, gerando tensões que muitas vezes revelam a sobreposição da utopia do amor romântico.

Costa (1999) observa o papel da cultura na transmissão do amor-paixão romântico, que é tido como garantia de felicidade, de modo que, se, por algum motivo, não obtemos sucesso nessa empreitada, sentimo-nos culpados, desvalorizados. Segundo esse autor, falta de posicionamento contra o valor imposto evidencia uma valorização geral da crença na universalidade e na bondade dessa forma de amar, restringindo nossa possibilidade de criar e explorar novas configurações amorosas.

Assim, talvez possamos compreender a experiência da mulher de permanência no sofrimento, nesse âmbito, como estando relacionada a uma dificuldade de acreditar e de buscar uma maneira diferente de relacionar-se sexual e afetivamente com o sexo oposto. Como sabemos, até hoje muitas mulheres crescem embalando os sonhos de encontrar, na vida adulta, um "grande amor", ou seja, um homem por quem ela se apaixonará, com quem casará, constituirá família, viverá para sempre, e feliz. Esse é um valor social que continua sendo transmitido pelos pais aos filhos, tendo um significado peculiar para as mulheres, em função, como já destacamos, do seu papel no contexto sócio-histórico brasileiro e, certamente, na maioria das culturas contemporâneas.

Como pudemos observar diante de tudo o que expusemos, parece existir uma estreita vinculação entre sofrimento, gênero e amor-romântico. Isso nos faz pensar na importância de considerarmos os processos culturais e históricos na compreensão do fenômeno em estudo, pois este não existe fora do tempo e do espaço.

\section{Método}

Este estudo inspirou-se no método fenomenológico. Tal estratégia de investigação enfatiza os fenômenos humanos diferentemente do paradigma cientificista, o qual, segundo alguns autores (Triviños, 1987; Minayo, 1994; Figueiredo, 1999; Roehe, 2006; Critelli, 2006), concebem o envolvimento do pesquisador com os participantes da pesquisa como um aspecto que pode comprometer o de- senvolvimento da investigação. A modalidade de pesquisa de inspiração fenomenológica tem como objetivos "acessar o mundo privado e subjetivo do homem e dar conta de dimensões do vivido humano não mensuráveis pela metodologia quantitativa tradicional" (Holanda, 2001, p. 38). Sendo assim, valoriza-se não a explicação, mas a compreensão dos fenômenos vivenciados, os quais se manifestam pela experiência singular de cada pessoa. Assim, buscando compreender a experiência de sofrimento de mulheres na relação amorosa, adotamos a fenomenologia não somente como um método de pesquisa, mas, de acordo com Critelli (2006), como uma forma de compreensão do ser humano.

A fenomenologia teve origem no pensamento de Edmund Husserl e data do início do século XX. Ela surgiu posicionando-se contrária ao modelo positivista de ciência, fazendo-nos pensar o homem como um ser que atribui sentido ao mundo e cuja existência é marcada pela fluidez e movimento constante de construção de si mesmo. Portanto, não se compreende a existência humana a partir de verdades imutáveis e fixas, pois, conforme lembra Dutra (2002), o homem é um ser de abertura e de relação.

Neste trabalho, buscamos compreender a mulher através de um de seus infinitos modos de existir, manifestados pela experiência de sofrimento amoroso.

\section{Procedimentos}

Nesse percurso os procedimentos consistiram na seleção de 06 (seis) mulheres que estavam vivendo essa experiência que buscamos investigar. A idade variou entre 25 (vinte e cinco) e 55 (cinquenta e cinco) anos, considerando-se essa faixa etária presente em nossa clientela. Para selecionar as depoentes, solicitamos às pessoas conhecidas que nos indicassem mulheres que demonstravam estar vivendo uma situação de sofrimento na relação amorosa. Informamos a essas pessoas sobre a temática dessa pesquisa, explicamos que a indicação só deveria ser feita mediante a permissão das possíveis participantes, que o conteúdo da entrevista seria confidencial e que o sigilo acerca da identidade de cada entrevistada seria preservado. Quanto a esse aspecto, solicitamos que tais pessoas, ao receberem a confirmação da participação da pessoa indicada mantivessem sigilo. Desse modo, foi constituído um grupo de seis mulheres que foram entrevistadas individualmente. As seis primeiras mulheres indicadas apresentaram relatos que, segundo o nosso entendimento, contemplavam o objeto de estudo proposto.

$\mathrm{O}$ instrumento utilizado para ter acesso à experiência investigada foi a entrevista semi-dirigida, em que as participantes davam um depoimento da sua experiência, a partir da seguinte pergunta disparadora: Você pode me falar sobre como está sendo a sua vida amorosa? Além disso, elaboramos previamente um roteiro contendo algumas questões a serem abordadas ao longo dos depoi- 
mentos, relacionadas a projeto de vida e relacionamento amorosos; influência da dinâmica familiar no modo de ser e de viver a relação amorosa; o lugar do prazer e bem-estar no amor; o papel desempenhado por cada parceiro da díade e ocupação dos espaços público e privado; o real e o ideal na relação de amor.

Foi realizada uma entrevista individual com cada participante, cuja duração variou entre uma hora e uma hora e quarenta minutos, em local e horário agendados previamente e a critério de cada participante. Todas as participantes autorizaram, mediante assinatura do Termo de Consentimento Livre e Esclarecido, a gravação das entrevistas e posterior publicação dos resultados. Cabe salientar que esta pesquisa seguiu os critérios estabelecidos pela Resolução 196/96 do Conselho Nacional de Saúde (CNS). Neste trabalho, os nomes das participantes foram substituídos por nomes fictícios.

Para compreender a experiência em questão, recorremos à estratégia da narrativa, tal como denominada por Walter Benjamin (1994) e sistematizada por Schmidt (1990), Dutra (2000), Morais (2004) e Maux (2008) em suas pesquisas. De acordo com aquele autor, a narrativa constitui a expressão da experiência humana, a qual só pode ser comunicada pelo próprio narrador, neste caso, as participantes da pesquisa. Ainda para Benjamin (1994), narrar é intercambiar experiências, é produzir sentidos.

As entrevistas foram gravadas em áudio e posteriormente transcritas. Em seguida, passaram por uma literalização, procedimento este que, de acordo com Schmidt (1990), consiste em transformar as falas dos depoentes em texto literário, de modo a deixá-lo o mais próximo possível da oralidade. De maneira semelhante à utilizada por Dutra (2000; 2002), após a legitimação das entrevistas como depoimentos, dialogamos com estes, fazendo comentários e interpretações, a partir das reflexões acerca dos sentidos das narrativas, interpretados à luz do referencial fenomenológico e humanista Centrado na Pessoa.

\section{Resultados e Discussão}

Iniciamos a apresentação dos resultados e discussão da pesquisa, ancorados no entendimento de que o sofrimento permanente na relação amorosa revela um modo de estar no mundo, de perceber-se na relação com os outros e consigo. Assim, ao falarem sobre a experiência aqui tratada, constatamos que várias participantes tiveram experiências de convívio familiar desfavorável ao desenvolvimento de um self receptivo ao livre fluir dos sentimentos. É o que evidenciam as seguintes narrativas:

Vera: (...) Tudo o que eu fazia dentro de casa minha mãe colocava defeito (...).

Isaura: (...) eu me sentia revoltada porque meus pais não explicavam o motivo, só faziam dizer: - Não faça isso! Entendeu?
A partir destas falas, podemos compreender a permanência no sofrimento amoroso como a expressão de um modo de ser e de se perceber constituído ao longo do tempo, especialmente na dinâmica familiar dessas mulheres, cujo clima psicológico parece não ter contribuído para a formação de um self alicerçado no fluxo de experiências. O que nos leva ao pensamento de Rogers (1961/1974), ao falar sobre a tendência que muitas pessoas têm de adotar um modo de vida baseadas em referências externas, ficando distantes de suas experiências reais, em virtude de na infância terem buscado fugir da sensação de ameaça da perda do amor dos pais.

Segundo esse autor, as atitudes avaliativas e pouco receptivas dos pais podem levar a criança a negar ou distorcer suas experiências reais. Ela busca, então, corresponder às expectativas alheias, preservando sua auto-imagem, bem como o apreço das pessoas que lhe são significativas. Dessa forma, a criança internaliza valores e atitudes de outrem como se fossem dela própria, aspecto este que dificulta a formação de um self maduro e saudável. Na situação em análise, podemos pensar que uma experiência dessa natureza poderá dificultar a construção por tais mulheres de uma relação amorosa ancorada na valorização da alteridade, na fluidez, na criatividade e no prazer.

Sofia percebe claramente a influência que os valores, normas e atitudes de sua mãe assim como os (...) dogmas espirituais (pecado, castigo de Deus, o que é certo ou errado) (...) exercem até hoje sobre o seu modo de ser, identificando-os como obstáculos à sua decisão de separar-se do marido. Além disso, ao dar-se conta de que já no início o casamento não estava bem, Sofia sentiu-se culpada, acreditando que a falta de desejo sexual do marido, que persistia até aquele momento, era um problema dela:

(...) eu achava que a culpa era minha; alguma coisa estava errada, mas eu sempre achava que esse erro estava em mim, não estava nele, não estava no relacionamento.

Vera deixa claro que, além do sentimento de culpa, a função de cuidar é marcante na experiência de vida das participantes:

Com o meu marido mesmo, se eu não fizer uma coisa para o meu marido, eu me sinto assim... culpada.

A função de cuidar é ressaltada por Diniz (2006), ao afirmar que a mulher geralmente dedica mais tempo cuidando do outro do que de si. Santos (2009), em seu estudo sobre gênero e saúde mental, conclui que " $a$ tarefa do cuidado é socialmente atribuída às mulheres que, mesmo estando doentes, não escapam de tal prescrição social".

Isso nos faz pensar na existência de um self estruturado em função do outro, de seus valores, necessidades 
e expectativas. Percebe-se nas narrativas de várias mulheres, que parece ser mais fácil sacrificar-se, assumir as dificuldades oriundas do relacionamento, abrir mão de projetos, enfim prejudicar-se, a ver o outro sofrer.

Os resultados da pesquisa também apontam a presença, em vários depoimentos, dos sentimentos de rejeição e desvalorização pessoal:

Vera: (...) Eu me sinto rejeitada dentro de casa, me sinto rejeitada na sociedade... Eu me sinto rejeitada por todo mundo (...).

Laura: O que eu passo, eu nunca dou muita importância, sempre acho que posso estar suportando. Eu digo a mim mesma assim... Não, eu... Não morro não... Passa!

Algumas participantes evidenciam também diferentes maneiras de perceber e expressar o sofrimento amoroso, sendo comum a manifestação de sintomas físicos e psíquicos:

Isaura: E hoje, esse amor que eu vivo, me sufoca, incomoda, eu fico agoniada (...). Assim, o meu sofrimento é tão grande, que eu não tenho vontade de viver... (...). Sofia: Eu atribuo essa depressão e esse pânico a todo esse processo que começou no início do casamento, até hoje... Esse período de depressão foi devido a todo esse processo assim de desprezo, de descaso, de não ter realmente o companheiro que eu imaginava, que eu queria ter, então chegou o momento em que caí completamente. Eu tinha uma expectativa diferente em relação ao meu casamento e acabei me adaptando à situação, então adoeci... bastante...

Fátima: Sempre eu tenho dor de cabeça, tenho uma agonia, uma coisa ruim... na cabeça. Eu acho que isso tudo está ligado aos problemas que eu vivo com o meu marido (...).

Nos depoimentos, é fácil imaginar a relação existente entre a vida amorosa das entrevistadas e o seu sofrimento, o qual se manifesta, comumente, através de reações emocionais, do problema de nervos, ou até mesmo da depressão e do pânico. Isso é uma evidência da importância que essas mulheres atribuem ao relacionamento amoroso, na medida em que estruturam suas vidas em torno desse relacionamento, como bem reconhece Vera:

É como que seja na, na base, na estrutura, assim de... de uma pessoa é o amor! Eu acho que é assim sabe? Não entendo muito, mas eu vejo assim. É assim que eu me sinto... Como se estivesse assim, desmoronando, sem ter estrutura!

Algumas expectativas e idealizações que as participantes nutriam em torno do parceiro e da relação amorosa são reveladas nas falas a seguir, fazendo-nos pensar que talvez todo o sofrimento pelo qual essas mulheres passam em suas relações amorosas esteja, pelo menos em parte, relacionado a essas expectativas e idealizações.

Elisa: (...) Não pensei que fosse assim, pensei que ia sair junto, cuidar dos filhos junto, tudo junto.

Fátima: Eu pensava que ia ser feliz com o meu marido, mas hoje em dia é bem difícil mesmo, bem complicado! Sofia: Ninguém casa para separar com um mês depois; a gente casa, pelo menos a minha ideia era essa: eu tinha vontade de envelhecer com ele. Eu ficava imaginando a gente velhinho com os netos... Então, é uma frustração muito grande.

De acordo com Levy e Gomes (2011), "no início de um relacionamento amoroso, é comum que as qualidades do parceiro sejam amplificadas e se acredite poder modificar, durante o transcorrer do mesmo, as características que pareçam indesejáveis" (p. 46). Quando as fantasias idealizadas no início da relação não se concretizam, o laço amoroso fica abalado, gerando insatisfação, como revelam essas narrativas.

Evidenciam também que alguns ideais do romantismo amoroso, tais como os de durabilidade e felicidade compõem os selves das entrevistadas, dando indícios de que essa forma de amar, como bem reconhece Costa (1999), apesar das mudanças ocorridas no contexto sócio-histórico desde o seu surgimento, há três séculos, ainda persiste no mundo ocidental. Vemos que esse ideal amoroso continua embalando os sonhos de muitas mulheres, em função da influência, ainda presente, de elementos de continuidade na imagem e no papel da mulher na realidade atual

É importante ressaltar que a busca pela autonomia e a valorização dos espaços individuais, embora almejadas, não parecem ser algo facilmente posto em prática pelas participantes deste estudo, ao contrário do que acontece com a maioria dos seus parceiros. Segundo o ponto de vista das mulheres entrevistadas, esses não demonstram interesse em fortalecer os espaços conjugais, aspecto que constitui uma queixa da maioria das participantes. Essa diferença de gênero na forma de viver o amor parece contribuir para o desencontro e o distanciamento do par amoroso, resultando em sofrimento. A fala de Elisa mostra a dificuldade de expandir e preservar seus espaços individuais, deixando claro que suas intenções geralmente não se concretizam:

Muitas vezes eu falo mais do que ajo, porque eu nunca saio assim com minhas amigas para um show, nunca fico até tarde na rua com minhas amigas... Não pode.

Vale salientar que em várias narrativas da pesquisa constatamos que a exclusividade, o prazer sexual e a durabilidade (aspecto já ressaltado) são fatores considerados pelas participantes como importantes na manutenção de um vínculo amoroso satisfatório. Esse dado parece guar- 
dar relações com o que foi observado por Garcia e Tassara (2001), em sua pesquisa. Essas autoras constataram que, para as mulheres que pesquisaram, a felicidade conjugal requer a existência de um relacionamento ancorado naqueles ideais do romantismo amoroso.

Entendemos que a maioria das participantes, ao encontrar o atual parceiro amoroso, acreditou que poderia viver uma relação ancorada nos valores do amor romântico aqui apontados, tomando tal relação como principal fator de bem-estar e auto-realização. Nesse sentido, sugerimos que a permanência no sofrimento amoroso pode estar relacionada a uma dificuldade dessas mulheres de alterar as suas crenças no amor, buscando repensar, como sugere Costa (1999), “(...) o que significa 'outro', 'companhia', 'felicidade', e 'ideal imortal' (...)” (p. 218-219). Dentro dessa linha de pensamento, estamos considerando que os selves dessas mulheres não se constituem apenas no meio familiar, mas se inserem em um contexto social e cultural mais amplo. Recorremos então a Neves (1997), ao afirmar que a sociedade contemporânea caracteriza-se pela força do controle que exerce sobre os indivíduos, agindo diretamente na produção de subjetividades.

De acordo com essa linha de pensamento, Guatarri e Rolnik (1986) acrescentam que o processo de produção é atravessado por representações que são injetadas nas pessoas, através da linguagem, da família, dos equipamentos coletivos que nos rodeiam e da mídia. Ressaltam que a disseminação geral do poder capitalista produz efeitos sobre as diversas esferas da vida - inclusive as diferentes configurações das relações cotidianas - produzindo subjetividades avessas ao diferente, ao inesperado, ao movimento de ruptura com o instituído.

Assim, cristalizadas em um modo de ser previsível e categorizado, essas mulheres parecem alheias ao poder-ser do qual nos fala Dutra (2000), ou seja, à sua capacidade de crescimento e desenvolvimento contínuos, na busca por mudanças instauradoras de um modo construtivo de viver, apesar dos percalços inerentes ao próprio existir.

O depoimento de Vera expressa bem esse aspecto que vimos discutindo, pois revela uma trajetória de vida marcada por conflitos decorrentes do anseio de liberdade, de ruptura com os padrões e normas pré-estabelecidos e impostos sobre o seu modo de ser, como ela bem explicita a seguir:

Então, estava tudo planejado para mim: eu ia fazer esse curso, ia trabalhar, casar e ter filhos. E eu não queria que fosse assim, queria me soltar... Assim, para a vida. Mas era uma coisa errada, que eu queria, não é?

É interessante observar que as decepções e frustrações na vida amorosa das entrevistadas contribuem para o desenvolvimento de um modo de ser descrente na experiência do amor, na possibilidade de buscar uma maneira diferente de amar. Assim revela Laura:
Se a gente se separar, eu nem penso em arranjar outro, eu sempre penso que saindo dessa complicação que eu... disso aqui que eu arranjei para a minha vida, que só fez complicar, eu jamais tenho outra pessoa. Eu acho que não ia dar certo. É tão difícil relacionamento! Eu achava que esse ia dar certo, mas não deu.

Em todas as narrativas, percebemos uma fala que aponta os motivos pelos quais as participantes continuam na relação amorosa, apesar de se queixarem de todo o sofrimento pelo qual vêm passando, e que geralmente atribuem a tal relação ou ao parceiro. Assim, elas evidenciam a singularidade de suas experiências, o que nos faz ver que, entre algumas entrevistadas, há motivos em comum, tais como o medo da solidão, o fato de acharem que gostam do parceiro, as dificuldades de cuidarem sozinhas dos filhos e a esperança de melhoria do seu relacionamento amoroso. Os trechos a seguir também mostram que essas mulheres buscam uma compreensão para a realidade que vivenciam:

Vera: (...) eu não me acho capaz, está entendendo? Não me acho com capacidade de segurar a barra sozinha. A vida é difícil...

Sofia: (...) é o medo de ficar só, de todo mundo pensar que eu estou disponível para qualquer pessoa... Eu tenho esse medo... O medo de eu chegar em um lugar e ser desprezada porque eu sou uma mulher separada (...).

Embora para algumas mulheres não esteja totalmente claro o motivo ou os motivos de sua permanência no sofrimento amoroso, havendo, na maioria dos casos em questão, mais de uma razão consciente e aparente, nos chama a atenção nessas falas a importância atribuída por tais mulheres à existência de um "outro", o parceiro amoroso, em suas vidas. Essas mulheres sentem-se receosas e incapazes de conduzirem e administrarem sozinhas a própria existência e as dificuldades que imaginam enfrentar após um possível rompimento amoroso.

Segundo Ligeiro e Barros (2008), o medo do abandono pelo parceiro e da perda do seu amor são constitutivos da subjetividade feminina. Para as autoras, uma situação de separação amorosa leva a mulher a vivenciar uma espécie de perda de si mesma, de aniquilamento. É como se ela só se reconhecesse como tal através da experiência de ser amada por um homem.

Assim, percebemos que a maioria das participantes demonstra, nitidamente, um modo de ser pessimista e descrente na própria capacidade de mudar o rumo da sua existência, de buscar outras possibilidades de estar no mundo, extraindo prazer e satisfação do processo de viver. Portanto, o que parece subjacente em quase todos os relatos, e é explicitamente apontado por algumas das entrevistadas, é uma experiência de ser, de existir, marcada pelo medo da solidão, do abandono, de não ter valor e nem merecer amor. 
Tais expressões nos levam a pensar a permanência no sofrimento amoroso como a dificuldade dessas mulheres de se apropriarem de si mesmas, de suas vidas, dando-lhes uma direção mais satisfatória e reveladora de um novo modo de existir, fundamentado, talvez, no que Rogers (1963) denomina de autenticidade; ou seja, o movimento de abertura ao vivido. Essa abertura ao fluir dos sentimentos talvez seja a condição primordial para que tais mulheres possam aprender a estar sozinhas e a lidar com outros aspectos da sua subjetividade que dificultam a construção de um relacionamento amoroso ancorado na vivência da alteridade.

$\mathrm{Na}$ análise dos depoimentos, percebemos que geralmente as mulheres abrem mão de um projeto profissional, ou o interrompem, fazendo renúncias que geram, em alguns casos, a restrição aos tradicionais papéis de dona-de-casa e mãe, à medida que elegem a relação amorosa como primordial. Como nos lembra Costa (1999), o amor-romântico é vivenciado pelos parceiros como atributo essencial da felicidade por eles almejada. O que nos faz pensar na influência dos valores, normas e padrões comportamentais que, ao lado das conquistas femininas, ainda permeiam a autoimagem da mulher em nossa sociedade, contribuindo para a sua permanência no sofrimento amoroso.

Em quase todas as narrativas, percebemos, de forma acentuada, as iniquidades de gênero presentes no convívio da díade amorosa, como podemos observar na fala de Fátima:

Meu marido acha que o homem pode tudo e a mulher não. Ele costuma pensar dessa maneira, que ele pode, ele pode sair que não tem problema nenhum; agora se eu sair ele já fica de orelha em pé. Se eu sair, se eu demorar, ele já fica muito chateado.

Essa fala deixa clara a existência do que se reconhece culturalmente como machismo ideológico, com a tentativa do parceiro da participante de exercer controle sobre a sua vida e de delimitar os papéis que cada integrante da díade amorosa deve exercer. Fagundes, Almeida, Andrade e Miranda (2009) expõem que vivemos em uma sociedade na qual imperam construções patriarcais e machistas que são mantidas pelos homens e pelas mulheres. Ambos são "produtos de uma sociedade patriarcal onde impera um discurso dominante que coloca a mulher em uma posição desprivilegiada e subalternizada em comparação aos homens" (p. 02). Assim, podemos pensar a permanência no sofrimento amoroso como a expressão das desigualdades de gênero presentes no cotidiano dessas mulheres, que não conseguem mais calar diante dessa situação. Embora, muitas vezes, suas ações não coincidam com suas reivindicações.

É interessante constatar que a maioria das entrevistadas revela a existência de projetos, o anseio por realizar algo que possibilite crescimento pessoal. Isso demonstra a possibilidade da emergência de novos sentidos para as suas existências, sem que precisem depositar na relação amorosa todas as suas expectativas de sucesso ou de fracasso, bem-estar ou sofrimento. No entanto, elas parecem não se apropriar de si mesmas, no sentido de buscarem, efetivamente, outras possibilidades de autorrealização. Permanecem, então, sofrendo na relação amorosa, talvez pelo medo da perda do sentido de suas vidas decorrente de um rompimento do casal. Sofia parece ter encontrado uma maneira de caminhar rumo a uma melhor compreensão e elaboração do seu sofrimento e da sua própria vida:

(...) para mim alivia muito falar, eu me sinto mais aliviada, eu tomo mais consciência do que está acontecendo comigo diariamente. Então, mesmo que eu não tenha outra pessoa, em determinado momento, mas eu falo para mim, eu falo só (...).

O trecho acima ilustra claramente que "a relação entre palavras e experiência aparece aqui como uma relação direta - a palavra diz a experiência, a experiência chama pela palavra” (Gendlin, 1973, p. 263). Assim, Sofia evidencia a importância de contar e recontar a sua história, pois, à medida que ouve a sua fala, vai desvelando os aspectos escondidos, unindo-os, integrando-os, dando-lhes um contorno que faça sentido.

\section{Considerações Finais}

A constatação, frequente em nosso cotidiano profissional, de queixas de mulheres sobre a permanência no sofrimento amoroso gerou indagações que apontavam para a singularidade da experiência aqui tratada, considerando-se os aspectos culturais e históricos que pareciam permear tal experiência. Esse processo de investigação partiu do entendimento de que o objeto desta pesquisa relaciona-se ao self, expressão da subjetividade humana. Nesse sentido, pudemos observar que a experiência investigada revela um modo de estar no mundo, o qual envolve sempre a co-existência, o papel e a influência dos outros nos diferentes contextos presentes ao longo da vida de cada mulher que foi entrevistada.

Conhecer o modo como se constitui a subjetividade das participantes desta pesquisa, considerando diferentes contextos, foi de suma importância para a compreensão que pretendíamos obter no trabalho. Nesta perspectiva, podemos pensar que permanecer no sofrimento amoroso:

- constitui uma experiência singular, embora permeada por questões históricas e culturais relativas à dimensão de gênero e aos ideais do amor-romântico, ainda presentes na atualidade;

- revela um modo de estar no mundo, constituído ao longo da vida de cada participante, nos diferentes contextos e caracterizado por sentimentos de baixa auto-estima, incapacidade, insegurança e medo; 
- revela, sobretudo, um self marcado pelo medo da solidão, do desamor, evidenciando a dificuldade das participantes de se apropriarem de suas vidas, dando assim origem a um modo de viver e de amar mais prazerosos.

A estratégia da narrativa mostrou-se pertinente para o nosso objetivo de apreender o sentido atribuído à experiência de sofrimento amoroso, na vida das participantes. Cabe lembrar que seus depoimentos denotam a importância e a necessidade de falarem livremente sobre suas respectivas experiências, expressando as emoções e sentimentos que as acompanham. Desse modo, salienta-se a importância de um espaço favorável à expressão e elaboração do sofrimento das mulheres que vivenciam essa experiência na vida amorosa. O que pode ocorrer por meio de aconselhamento psicológico, psicoterapia ou da formação de grupos de apoio. Entendemos que as instituições que fornecem apoio à mulher podem desempenhar um papel fundamental no desenvolvimento de ações que considerem a complexidade do sofrimento amoroso.

Chegar a este momento do trabalho reforça a ideia de que o ser humano está em constante devir, em permanente processo de construção da subjetividade e, portanto, da sua maneira de perceber a si próprio e ao outro, do seu modo de estar no mundo. Isso, por sua vez, nos faz pensar na mutabilidade e fluidez dos dados aqui obtidos, assim como nas infindáveis possibilidades de interpretação desses dados.

Entendemos que a experiência de sofrimento amoroso das participantes deste estudo existe num movimento incessante de mostrar-se e ocultar-se, não podendo, assim como o fluxo da vida, alcançar qualquer fixidez. A dinâmica do sentido de tal experiência acompanha a existência de cada mulher, sendo vista, de acordo com Critelli (1996), como o próprio sentido de ser (existir), cujo conhecimento é sempre relativo e provisório. Partindo desse princípio, temos o desejo de que a compreensão do objeto deste trabalho, aqui desvelada, seja importante e útil para os profissionais que lidam com tal problemática, possibilitando um enriquecimento na sua intervenção, no modo de estar com cada mulher que vive a experiência aqui tratada.

\section{Referências}

Almeida, S., \& Jablonski, B. (2011). O novo (velho) homem: o masculino nos livros de autoajuda. Arquivos Brasileiros de Psicologia, 63(2), 28-38.

Benjamin W. (1994). Obras escolhidas. Magia e técnica, arte e política. São Paulo: Brasiliense.

Biasoli-Alves, Z. M. M. (2000). Continuidade e rupturas no papel da mulher brasileira no século XX. Psicologia: Teoria e Pesquisa, 16(3), 233-239.
Braga, M. G. R. (2005). Maternidade e tecnologias de procriação: o feminino na contemporaneidade (Dissertação de Mestrado). Universidade Católica de Recife, Recife.

Costa, J. F. (1999). Sem fraude nem favor: estudos sobre o amor-romântico. Rio de Janeiro: Rocco.

Critelli, D. M. (2006). Analítica do sentido: uma aproximação e interpretação do real de orientação fenomenológica ( $2^{\mathrm{a}} \mathrm{ed}$.). São Paulo: Brasiliense.

Diniz, G. R. S. (2006). Modos de ser femininos, relações de gênero e sociabilidades no Brasil. Em C. S. Wolff, M. de Fáveri \& T. R. O. Ramos (Orgs.), Seminário Internacional Fazendo Gênero, Gênero e preconceitos: anais [online]. Florianópolis: Ed. Mulheres. [Citado 12 junho 2012]. Disponível na World Wide Web: HTTP://www.fafendogenero7.com.br/artigos/G/Glaucia_Diniz_05_B.pdf

Dutra, E. (2000). Compreensão de tentativas de suicídio de jovens sob o enfoque da abordagem centrada na pessoa (Tese de Doutorado). Instituto de Psicologia da Universidade de São Paulo, São Paulo.

Dutra, E. (2002). A narrativa como técnica de pesquisa fenomenológica. Estudos de Psicologia, 7(2). 371-378.

Fagundes, A. L. M., Almeida, A. S., Andrade, D., \& Miranda, H. (2009). Anais de Trabalhos Completos - XV Encontro Nacional da Associação Brasileira de Psicologia Social ABRAPSO. Disponível em: http://www.abrapso.org.br/siteprincipal/index.php?option=com_content\&task=blogcate gory\&id $=67 \&$ Itemid $=95$

Feres-Carneiro, T. (1998). Casamento contemporâneo: o difícil convívio da individualidade com a conjugalidade. Psicologia: Reflexão e Crítica, 11(2), 379-394.

Figueiredo, L. C. M. (1999). A invenção do psicológico: quatro séculos de subjetivação (1500-1900). São Paulo: Educ / Escuta.

Garcia, M. L. T. \& Tassara, E. T. O. (2001). Estratégias de enfrentamento do cotidiano conjugal. Psicologia: Reflexão e Crítica, 14(3), 635-642.

Gendlin, E. (1962). Experiencing and the creation of meaning. New York: The Free Press of Glencoe.

Gendlin, E. (1973). Experiencial Phenomenology. Em M. Natalson (Org.), Phenomenology and the social sciences. Evaston, Northwestern University Press.

Giddens, A. (1993). A transformação da intimidade. Sexualidade, amor e erotismo nas sociedades modernas. São Paulo: Editora Unesp.

Guatarri, F. \& Rolnik, S. (1986). Micropolítica: cartografias do desejo. Petrópolis: Vozes.

Levy, L. \& Gomes, I. C. (2011). Relações amorosas: rupturas e elaborações, Revista Tempo psicanalítico, 43(1), 45-57.

Holanda, A. F. (2001). Pesquisa fenomenológica e psicologia eidética: elementos para um entendimento metodológico. Em M. A. T. Bruns, \& A. Holanda (Orgs), Psicologia e Pesquisa Fenomenológica: reflexões e perspectivas (p. 35-55). São Paulo: Ômega. 
Ligeiro, V. M., \& Barros, R. M. M. (2008). Violência e poder: repercussões no feminino - A violência do abandono na mulher. III Congresso Internacional de Psicopatologia Fundamental e IX Congresso Brasileiro de Psicopatologia Fundamental (Anais). Disponível em: http://www.fundamentalpsychopathology.org/pagina-mesas-redondas-454 (Acessado em maio de 2012).

Maux, A. A. B. (2008). Do útero à adoção: a experiência de mulheres férteis que adotaram uma criança (Dissertação de Mestrado em Psicologia). Universidade Federal do Rio Grande do Norte, Natal.

Maux, A. A. B., \& Dutra, E. (2010). A adoção no Brasil: algumas reflexões. Estudos e Pesquisas em Psicologia (UERJ), 10(2), 356-372.

Medeiros, L. F. (2003). Sofrimento solitário, mal-estar compartilhado: um estudo sobre a doença dos nervos (Dissertação de Mestrado). Universidade Federal do Rio Grande do Norte, Natal.

Minayo, M. C. S. (1994). Ciência, técnica e arte: o desafio da pesquisa social. Em M. C. S. Minayo (Org.), Pesquisa Social: teoria, método e criatividade (pp. 09-29). Petrópolis: Vozes.

Morais, S. R. S. (2004). Ser-no-mundo com a criança portadora de câncer: compreendendo a experiência de psicólogos nos serviços de oncologia pediátrica de Natal - RN (Dissertação de Mestrado). Universidade Federal do Rio Grande do Norte, Natal.

Negreiros, T. C. G. M. \& Féres-Carneiro, T. (2004). Masculino e feminino na família contemporânea. Estudos e Pesquisas em Psicologia (UREJ), 4(1), 34-47.

Neves, C. A. B. (1997). Sociedade de controle, o neolioberalismo e os efeitos de subjetivação. Em A. E. Silva et al (Orgs.), Subjetividade: questões contemporâneas, n. 06, (pp.84-96). São Paulo: Hucitec.

Rebouças, M. S. S., \& Dutra, E. M. S. (2011). Não nascer: algumas reflexões fenomenológico-existenciais sobre a história do aborto. Psicologia em Estudo (Maringá), 16(3), 419-428.

Roehe, M. V. (2006). Uma abordagem fenomenológico-existencial para a questão do conhecimento em psicologia. Estudos de Psicologia (Natal), 11(2), 153-158.

Rogers, C. (1959). A Theory of Therapy, Personality, and Interpessonal Relationship, as Developed in the ClientCentered Framework. Em S. Koch (Ed.), Psychology, a Study of a Science, 3, pp.184-246. New York: Mc Graw-Hill.
Rogers, C. (1963). The actualizing tendency in relation to "motives" and to consciousness. Em M. Jones (Ed.), Nebraska Symposium on Motivation (p. 01-24). Nebraska: University of Nebraska Press.

Rogers, C. (1974). Tornar-se Pessoa. Lisboa: Morais (Original publicado em 1961).

Santos, A. M. C. C. (2009). Articular saúde mental e relações de gênero: dar voz aos sujeitos silenciados. Ciência \& Saúde Coletiva, 14(4), 1177-1182.

Schmidt, M. L. S. (1990). A experiência de psicólogas na comunicação de massa (Tese de Doutorado). Instituto de Psicologia da Universidade de São Paulo, São Paulo.

Silva, T. G. (2000). A liberdade é lilás: a trajetória das organizações feministas em Mossoró/RN (Dissertação de Mestrado em Ciências Sociais). Universidade Federal do Rio Grande do Norte, Natal.

Triviños, A. N. S. (1987). Introdução à pesquisa em ciências sociais: a pesquisa qualitativa em educação. São Paulo: Atlas.

Vaitsman, J. (2001). Gênero, identidade, casamento e família na sociedade contemporânea. Em R. M. Muraro \& A. B. Puppin (Orgs.). Mulher, gênero e sociedade (p. 13-20). Rio e Janeiro: Relume-Dumará/FAPERJ.

Ana Regina de Lima Moreira - Psicóloga com Graduação e Mestrado pela Universidade Federal do Rio Grande do Norte. Atualmente é psicóloga da Prefeitura Municipal de Parnamirim e Docente do Curso de Psicologia do UNIFACEX (Centro Universitário Facex), Natal, RN. Endereço Institucional: Rua Orlando Silva, 2896 - Capim Macio - Natal/RN, CEP 59080-020. Email: anaregina@facex.com.br; a.moreira2005@ig.com.br

Elza Maria do Socorro Dutra - Psicóloga, Doutora em Psicologia e Docente do Programa de Pós-graduação em Psicologia na Universidade Federal do Rio Grande do Norte (UFRN).Email: elzadutra.rn@gmail.com

Recebido em 26.10.12 Primeira Decisão Editorial em 11.04.13 Segunda Decisão Editorial em 25.04.13 Aceito em 05.05.13 